\title{
Adipocyte Derived Mesenchymal Stromal Cell and Platelet Lysate: Ideal Cell and Supplement for the Treatment of Immune-Inflammatory Diseases?
}

\author{
Felipe Rodrigues',2, Annelise Pezzi1,2,3, Álvaro Laureano1,2, Vanessa Valim 1,2,3, \\ Bruna Zambonato1,2,3, Alice Dahmer1,2,3, Letícia Baggio1,2, Filipe Sehn1,2,3, \\ Ianaê Wilke1,2,3, Maria Aparecida L. da Silva',2, Bruna Amorin',2* \\ ${ }^{1}$ Cellular Therapy Center, Hospital de Clínicas de Porto Alegre, Porto Alegre, Brazil \\ ${ }^{2}$ Laboratory of Cell Culture and Molecular Analysis of Human Cells, Hospital de Clínicas \\ de Porto Alegre, Porto Alegre, Brazil \\ ${ }^{3}$ Post-graduation in Medicine: Medical Sciences, Federal University of Rio Grande do Sul, \\ Porto Alegre, Brazil \\ Email: felipe.vfr@gmail.com, annepezzi@gmail.com, alvaro@brasaodopampa.com.br, \\ vanessavalim@gmail.com, bruna.zambonato@gmail.com, alicedahmer@gmail.com, \\ leticiabaggio@hotmail.com, flipersehn@gmail.com, ianaewilke@bol.com.br, \\ mariacida18@hotmail.com, ${ }^{*}$ bruamorin@gmail.com
}

Received 26 January 2016; accepted 31 May 2016; published 3 June 2016

Copyright (C) 2016 by authors and Scientific Research Publishing Inc.

This work is licensed under the Creative Commons Attribution International License (CC BY). http://creativecommons.org/licenses/by/4.0/

(c) (i) Open Access

\section{Abstract}

Background: Mesenchymal stromal cells (MSC) are being tested for the treatment of immune diseases. MSC are present in several adult tissues which milieu may influence MSC behavior particularly under inflammatory conditions. Additionally, culture conditions also can modify cell function or state of activation. Methods: To address the influence of the MSC source on its characteristics, we studied a xenofree, platelet lysate supplemented MSC from dental pulp, adipose tissue and bone marrow, co-cultured with isolated T cells and PBMC subset, and studied the effect of culture animal or human supplements immunomodulatory effect. Results: All three sources were efficient in inhibiting T cells. Among all MSC sources, as also described by others, adipose MSC was capable to significantly induce Treg phenotype and decrease $\mathrm{T} \mathrm{CD8}{ }^{+}$. Furthermore, comparing fetal bovine serum and platelet lysate, results demonstrate that platelet lysate alone is capable to induce immunomodulatory phenotype. Additional studies have to be made to elucidate the PL immunomodulatory effect.

\footnotetext{
"Corresponding author.

How to cite this paper: Rodrigues, F., Pezzi, A., Laureano, Á., Valim, V., Zambonato, B., Dahmer, A., Baggio, L., Sehn, F., Wilke, I., da Silva, M.A.L. and Amorin, B. (2016) Adipocyte Derived Mesenchymal Stromal Cell and Platelet Lysate: Ideal Cell and Supplement for the Treatment of Immune-Inflammatory Diseases? CellBio, 5, 15-25.

http://dx.doi.org/10.4236/cellbio.2016.52002
} 


\section{Keywords}

\section{Mesenchymal Stromal Cells, Dental Pulp, Adipose Tissue, Bone Marrow, T Cells Immunomodulatory Effect}

\section{Introduction}

Mesenchymal stromal cells are a specialized adult stem cell type of mesodermal origin. First identified by Friednstein [1] [2] in fibroblasts colony forming units from the bone marrow (BM), these cells are plastic adherent and capable of differentiation in chondrocyte, osteocytes and adipocytes. After its discovery, BM MSC regenerative potential has been explored in pre-clinical and clinical studies focusing on trans-differentiation and tissue engineering [3]. An increasing number of evidences, however, pointed to a regenerative and immunemodulatory role mediated by cell-to-cell contact and paracrine effects mediated by cytokines, growth factors, and exossomes [4] [5]. Apparently, MSC is microenvironment modulators that respond to small stimuli to maintain tissue homeostasis. MSC has been identified in most of the adult tissues, like liver; adipose tissue; lungs; heart; dental pulp; muscle; cord blood; placenta, synovial membrane and tendons [6].

Alternatives to BM MSC have been explored particularly outside the setting of bone marrow transplantation, and usually discarded tissue sources become an attractive option. Lipoaspirate, placenta, umbilical cord blood, umbilical cord, and teeth are amongst discarded tissue studied the most [7]. The role of the MSC source on its regenerative and immunemodulation effects, has been studied and although adipocyte derived MSC appears to have a higher proliferative and immunomodulatory potential, there still have conflicting results concerning the role of MSC source [8].

Concerns about xenoreactions to fetal calf serum supplemented cultured cells for cellular therapy, led our group [9] and others [10] to explore human derived supplements. As shown in our previous study, in platelet lysate (PL) supplemented cultures, MSC proliferates significantly better then when cultured with FCS [9]. Along with a higher proliferative index, PL could also alter MSC characteristics and its efficacy, leading to concerns about using fetal bovine serum and other non-human materials, evidence ensuring this is that MSC proliferates better using human derived materials, like platelet lisate (LP). As a strategy to consolidate human alternatives, this study was conducted using LP as culture supplement.

MSCs from different origins have common nomenclature and characterization as stated by the International Society for Cellular Therapy [11]. The possibility that MSC from different sources can induce distinct immunomodulatory profiles, is not yet entirely clear [12]. Through cell contact and paracrine mechanisms, several types of immune cells are regulated by MSCs. According to the desired effect in its clinical application, the definition of the best MSC source type is important in order to enhance therapeutic benefits. In the present study, we explored the immunomodulatory effect of MSC from dental pulp of human exfoliated deciduous teeth (SHED), adipose tissue (AD) and bone marrow (BM) with PBMC and magnetically isolated T lymphocytes, as well as the possible effect that FCS and PL supplements can affect MSC behavior.

\section{Material and Methods}

\subsection{Isolation, Expansion and Characterization of Mesenchymal Stromal Cells}

Mesenchymal stromal cells were collected after donor agreement and informed consent, according to the local ethical committee. MSC were cultured with DMEM low glucose (Gibco, Invitrogen Corp., USA), $1 \%$ PENSTREP (Gibco, Invitrogen Corp., USA), and $10 \%$ platelet lysate (PL) or $10 \% \mathrm{FCS}$, at $37^{\circ} \mathrm{C}$ and $5 \% \mathrm{CO}_{2}$. At $80 \%$ confluence MSC were detached with trypsin enzyme digestion, counted and replated. MSC were plated at $3 \times 10^{5}$ cells $/ \mathrm{cm}^{2}$ at $\mathrm{P}_{0}$ and $5 \times 10^{3}$ cells $/ \mathrm{cm}^{2}$ for following passages. PL was produced in house. Briefly, platelets passed through freezing and thawing cycle, centrifuged 4 times at $3000 \mathrm{~g}$ for $30 \mathrm{~min}$, sterilized through $0.22 \mu \mathrm{m}$ filter, heparinized and stored in $-20^{\circ} \mathrm{C}$ freezer for up to 3 months [9].

\subsection{Detection of Cell Viability}

Trypan blue viability assay was performed on cells before culture Viability percentage was determined using a 
Neubauer haemocytometer chamber after staining the cells with $0.4 \%$ trypan blue. The accepted mean viability was over $90 \%(87 \%-99 \%)$.

\subsection{Adipose Derived Mesenchymal Stromal Cells (AD-MSC)}

AD-MSC isolation was modified from Zuk et al. [13]. Briefly, 40 - $60 \mathrm{~mL}$ lipoaspirate was collected from plastic surgery procedure. Whole material was washed 3 times with PBS using a seringe in a 1:1 volume proportion. Wash lipoaspirated adipose tissue was then incubated with $0.2 \%$ type I collagenase solution in a 10:1 volume for 30 minutes in $37^{\circ} \mathrm{C}$, vigorously agitating at each 10 minutes. Cells were centrifuged at $800 \mathrm{~g}$ for $10 \mathrm{~min}$, pellet was incubated in $\mathrm{NH}_{4} \mathrm{CL}$ erythrocyte lysing solution for $10 \mathrm{~min}$, centrifuged at $400 \mathrm{~g} 10 \mathrm{~min}$, counted and cultured as stated above.

\subsection{Bone Marrow Mesenchymal Stromal Cell (BM-MSC)}

BM-MSCs were isolated from normal donor bone marrow harvest for transplant or transplant-discarded filters. In brief, filters were washed with $200 \mathrm{~mL}$ PBS (Gibco, Invitrogen Corp., USA); cells were centrifuged at $400 \mathrm{~g}$ 10 min, counted and cultured as stated above [14].

\subsection{Human Exfoliated Deciduous Teeth Mesenchymal Stromal Cells (SHED-MSC)}

Cells were extracted as previously described [15]. Briefly, completely healthy deciduous teeth were extracted and transported in PBS or culture medium. Cells were extracted from dental pulp with dentin curette. Dental pulp was placed in $0.2 \%$ type I collagenase and incubated at $37^{\circ} \mathrm{C}$ for $1 \mathrm{~h}$. Cells were centrifuged at $800 \mathrm{~g}$ for 10 min, washed $2 \times$ with PBS and cultured in 12 well plates.

\subsection{Mesenchymal Osteocyte, Adipocyte and Chondrocyte Differentiation}

Osteogenic, adipogenic and chondrogenic differentiation were performed in all cultures. Osteogenic differentiation was induced in Dulbecco's modified Eagle's medium low glucose (DMEN Low) (Gibco, Invitrogen Corp., USA), FCS (Gibco, Invitrogen Corp., USA), ascorbic acid ( $0.2 \mathrm{mmol} / \mathrm{L})$ (Acros Organics, Belgium), $\beta$-glycerophosphate $(10 \mathrm{mmol} / \mathrm{L})$ (Sigma-Aldrich, St. Louis, MO, USA) and dexamethasone $(0.1 \mu \mathrm{mol} / \mathrm{L})$, (Hypofarma, Brasil) for 30 days. Adipogenic differentiation was induced in Iscove's Modified Dulbecco's IMDM (Gibco, Invitrogen, USA) supplemented with $20 \%$ platelets poor human plasma, heparin $(5.000 \mathrm{UI} / \mathrm{ml})$ (Eurofarma, Brasil), indomethacin $(0.2 \mathrm{mmol} / \mathrm{L})$ (Merck Sharp \& Dohme, USA) dexamethasone $(0.1 \mu \mathrm{mol} / \mathrm{L})$, and insulin $(10$ $\mu \mathrm{mol} / \mathrm{L}$ ) (Eli Lilly, Mexico). Chondrogenic differentiation was induced in DMEM Low supplemented with insulin (Cellofarm, Brazil), ascorbic acid and TGF- $\beta$ (Invitrogen, USA). Osteogenic, adipogenic and chondrogenic differentiation were stained by Alizarin Red staining (Sigma-Aldrich, St. Louis, MO, USA), Oil Red (SigmaAldrich, St. Louis, MO, USA), and Alcian Blue (Sigma-Aldrich, St. Louis, MO, USA), respectively.

\subsection{PBMC and T Cell Isolation}

Venous blood was collected from healthy donors. Mononuclear cells were isolated by gradient centrifugation in histopaque (Gibco, Invitrogen, USA). Cells were washed $2 \times$ in PBS, counted and cultured with RPMI low glucose (Gibco, Invitrogen, USA), 1\% PENSTREP (Gibco, Invitrogen, USA) and 10\% fetal bovine serum (FBS) or LP. For T cell isolation, PBMC were passed through magnetic column (MACS; Miltenyi Biotec) according to the manufacturer instructions; cells were counted and cultured with RPMI low glucose (Gibco, Invitrogen Corp., USA), 1\% PENSTREP (Gibco, Invitrogen Corp., USA) and 10\% fetal bovine serum (FBS) or LP. T cells were obtained from PBMC by cultivation with fitohemaglutinin (PHA) at $10 \mu \mathrm{g} / \mathrm{mL}$ for 3 days.

\subsection{Comparison of Proliferative Potential of MSC}

MSC from all sources were expanded until passage five for comparison of proliferative potential. Population doubling point formula was used to estimate the cell proliferation based on the time in culture, number of plated cells and the number of cells at moment of trypsinization at the chosen passage. $A=n^{\circ}$ trypsinized cells; $B=n^{\circ}$ plated cells; $\mathrm{C}=\mathrm{n}^{\circ}$ hours in culture. 


$$
\frac{\operatorname{LOG}\left[\frac{A-B}{2}\right]}{C}
$$

\subsection{Co Culture Experiments}

Protocol was adapted from Le Blanc et al. [16]. In brief, after 3 days of lymphocytes expansion, they were incubated with $5 \mathrm{mM} \mathrm{CFSE} \mathrm{(Life} \mathrm{Technologies} \mathrm{Invitrogen),} \mathrm{according} \mathrm{to} \mathrm{the} \mathrm{manufacturer} \mathrm{instructions.} \mathrm{MSC}$ were cultured until the 2nd passage, trypsinazed and washed. Lymphocytes and MSC were plated at 10:1 proportion for a concentration of $1 \times 10^{6} / \mathrm{mL}$ lymphocytes. Cells were cultured for 3 days for proliferation and then supernatant containing lymphocytes were collected and analyzed by flow cytometry.

\subsection{Flow Cytometry}

Lymphocytes and MSC viable cells were counted and adjust for a concentration of $2 \times 10^{6} \mathrm{cell} / \mathrm{mL}$ in PBS, the cells were distribute in flow cytometry tubes $(50 \mu \mathrm{L} /$ tube), $5 \mathrm{uL}-10 \mathrm{uL}$ of the following antibodies CD90, CD73, CD105 CD3, CD14, CD45, CD34, CD19, HLDR MSC markers; CD3, CD4, CD8 lymphoid markers; CD4 CD25, FOXP3 Treg markers; CD3, CD56 NK markers; CD19 B cell marker. Cells were incubated for 30 min at $4^{\circ} \mathrm{C}$, protected from light. Next, cells were centrifuged at $400 \mathrm{~g}$ for $10 \mathrm{~min}$ to remove the unbound antibodies and resuspended in $0.5 \mathrm{~mL}$ PBS. The cells were assayed in a flow cytometer (FACS Canto II, Becton Dickinson) and the data analyzed with Cell Quest software (Becton Dickinson). MSC were defined by the expression of CD105, CD73, CD90 and the absence of HLA-DR, CD19, CD14, CD34 and CD45.

\subsection{Statistical Analysis}

For proliferation analyses were used one-way Anova and Tukey's Post Hoc; Paired T test was used when applicable.

\section{Results}

\subsection{Samples Description}

There were a total of 10 samples analyzed, three from BM and SHED, and four from adipose tissue. Table 1 describes the general characteristics of the samples.

\subsection{Mesenchymal Stromal Cell Imunophenotype from Three Distinct Sources}

Mesenchymal cells were analyzed by flow cytometry as stated in Methods, and MSC from all were characterized in accordance to the ISCT [11].

Table 1. MSC general characteristics.

\begin{tabular}{ccc}
\hline Source & Age & Gender \\
\hline SHED & 6 & $\mathrm{M}$ \\
SHED & 6 & $\mathrm{M}$ \\
SHED & 8 & $\mathrm{M}$ \\
BM & 24 & $\mathrm{M}$ \\
BM & 28 & $\mathrm{~F}$ \\
BM & 30 & $\mathrm{M}$ \\
AD & 33 & $\mathrm{~F}$ \\
AD & 22 & $\mathrm{~F}$ \\
AD & 34 & $\mathrm{~F}$ \\
AD & 26 & $\mathrm{~F}$ \\
\hline
\end{tabular}

F: Female; M: male; BM: bone marrow; AD: adipose tissue; SHED: dental pulp from human exfoliated deciduous teeth. 


\subsection{Mesenchymal Adipocyte, Chondrocyte and Osteocyte Differentiation}

All sources of MSC were able to multilineage differentiation in adipocytes, chondrocytes and osteocytes, as shown in Figure 1.

\subsection{Proliferation of BM-, SHED-, and AP-MSC}

Adipose derived MSC had a significantly $(\mathrm{p}=0.0017)$ better proliferation ratio, then the other sources in all passages. BM and SHED had no difference among them, as stated in Figure 2.

\subsection{MSCs Are Capable to Inhibit Lymphocyte Proliferation}

To answer if all three sources had the same immunomodulation potential, it was analyzed the capability of MSC to inhibit lymphocyte proliferation through CFSE by flow cytometry. All sources inhibited lymphocyte proliferation both in T and PBMC group, as showed in Figure 3.

\subsection{Immunophenotyping of T and PBMC Lymphocytes co Cultured with MSC}

To address if MSC could have different influence in lymphocytes subsets as a mechanism of action for their immunomodulation ability, the effect of MSC from each source on PBMC or isolated T cells subsets CD4, CD8, Treg, NK lymphocytes, and B cells were analyzed. MSC of all sources, except Adipocyte tissue, were able to tend to diminish all lymphocytes subsets in co-cultures experiments either with PBMC or T cells. SHED-MSCs were more efficient in significantly inhibiting PBMC derived Treg and TCD4 $4^{+}$cells $(p=0.01$ and $p=0.02$ respectively) then MSCs of any other source. On the other hand, AD-MSC had more profound and differential effects either when co-cultured with PBMC or isolated T cells. AD-MSC were able to statistically decreased ( $\mathrm{p}=$ 0.04 ) the number of B lymphocytes from PBMC, and when co-cultured with isolated T cells it significantly decreased $\mathrm{CD}^{+}(\mathrm{p}=0.008)$ and increased Treg $(\mathrm{p}=0.01)$ lymphocytes (Figure 4).

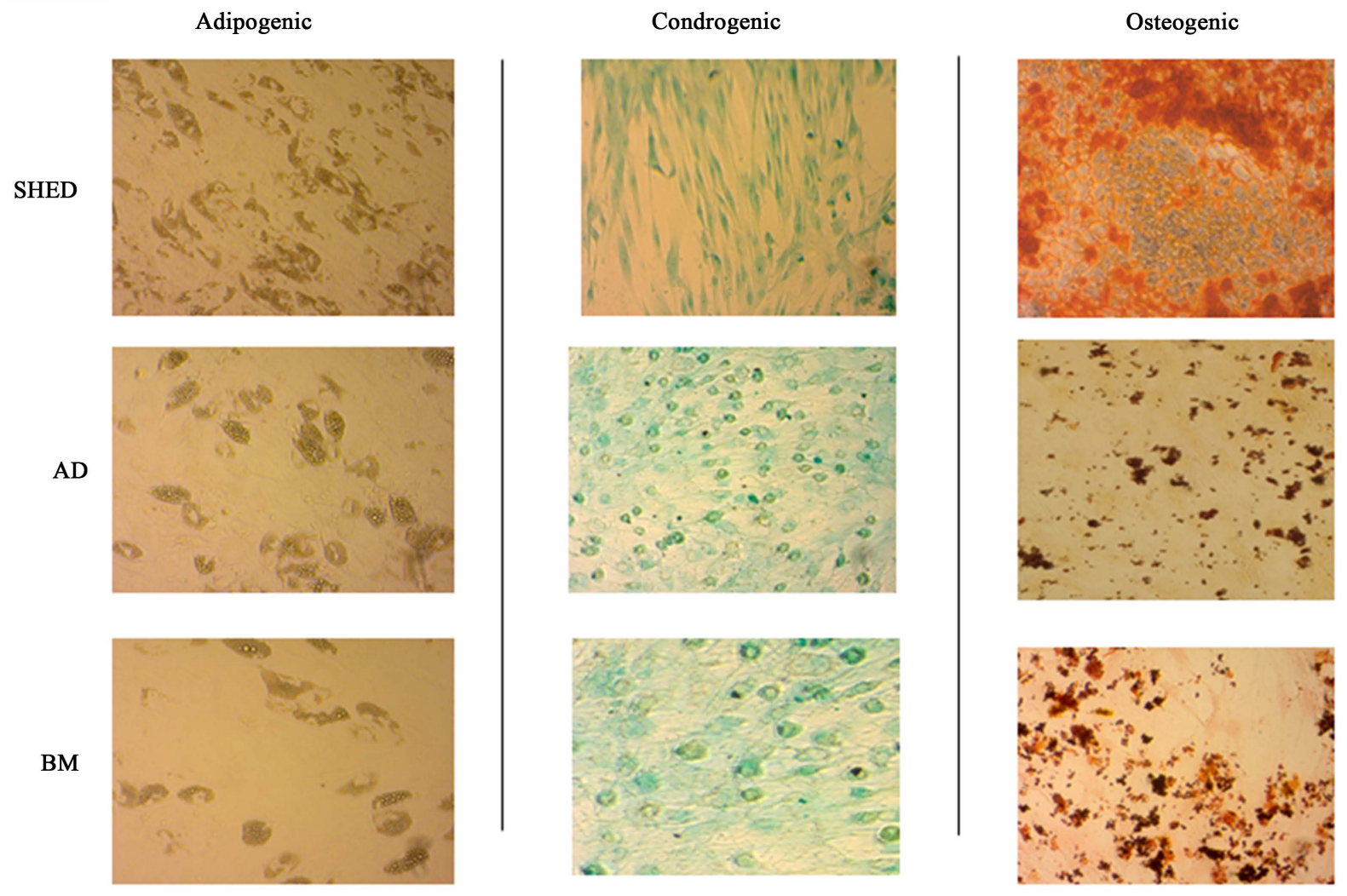

Figure 1. Multilineage differentiationl of BM-, SHED- and AP-MSC. 


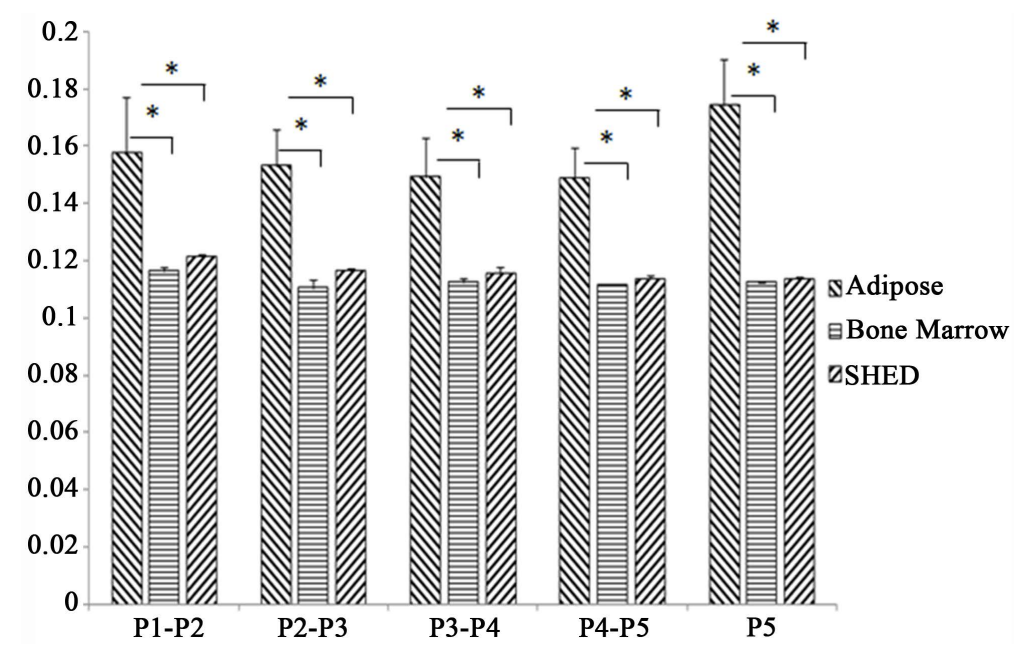

Figure 2. Proliferation comparison of bone marrow, human exfoliated deciduous teeth and adipose tissue MSC.

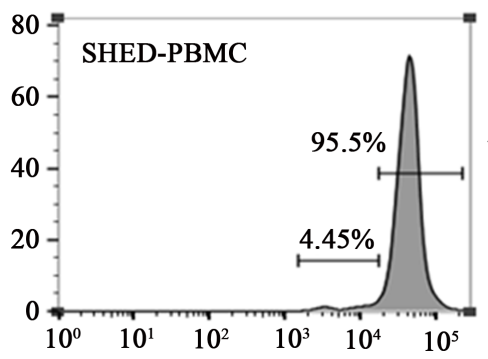

(a)

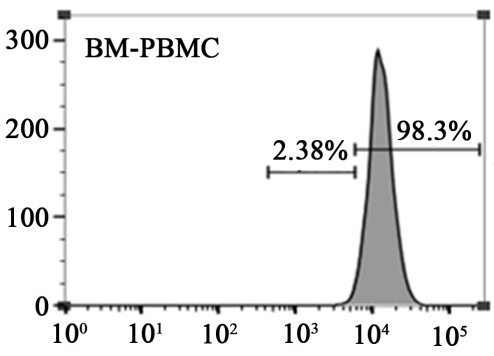

(b)

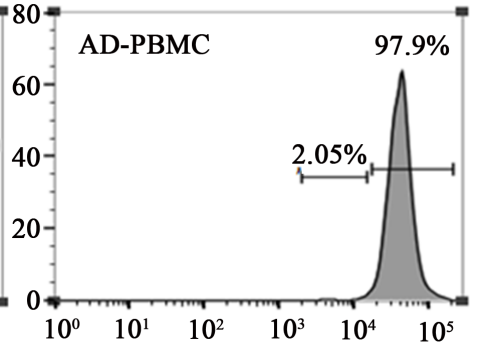

(c)

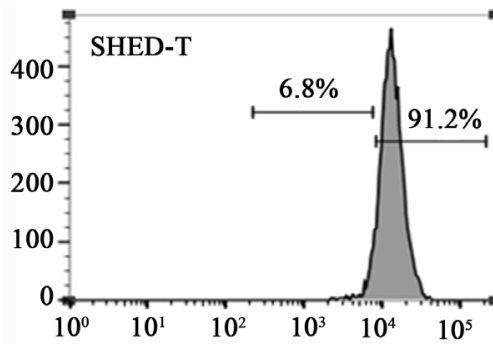

(d)

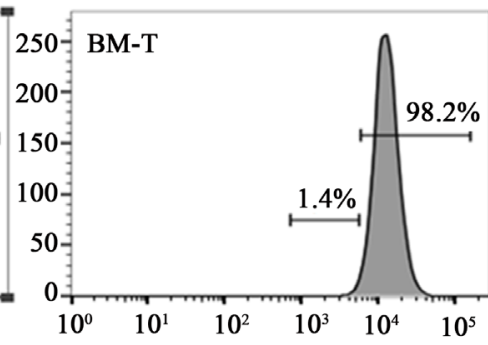

(e)

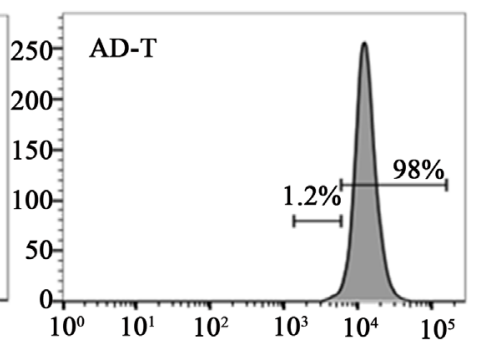

(f)

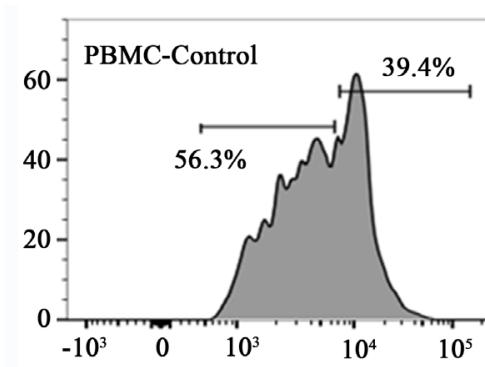

(g)

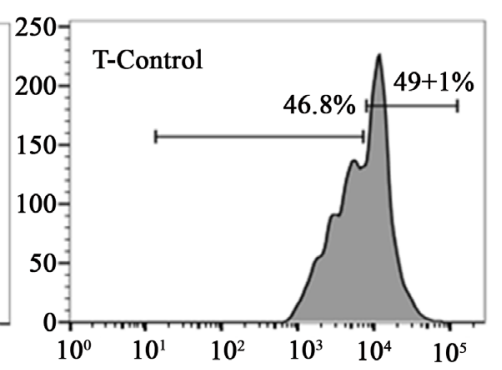

(h)

Figure 3. Effect of adipocyte derived MSC (AD-MSC), Human Exfoliated Deciduous Teeth derived MSC (SHED-MSC) and bone marrow derived MSC (BM-MSC) immunomodulation co cultured for 3 days with CFSE labeled isolated T cell and PBMC at 10:1 lymphocyte MSC ratio and controls. (a) SHED MSC co cultured with PBMC; (b) BM MSC co cultured with PBMC; (c) AD MSC co cultured with PBMC; (d): SHED MSC co cultured with magnetically isolated T cells; (e) BM MSC co cultured with magnetically isolated T cells; (f) AD MSC co cultured with magnetically isolated T cells; (g) PBMC control cultured in absence of MSC; (h): magnetically isolated T cells control cultured in absence of MSC. 


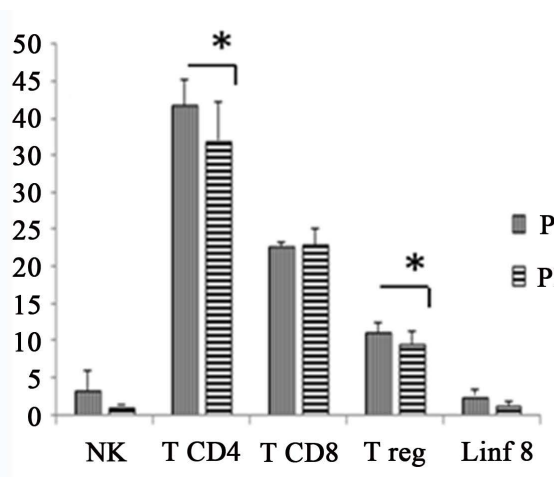

(a)

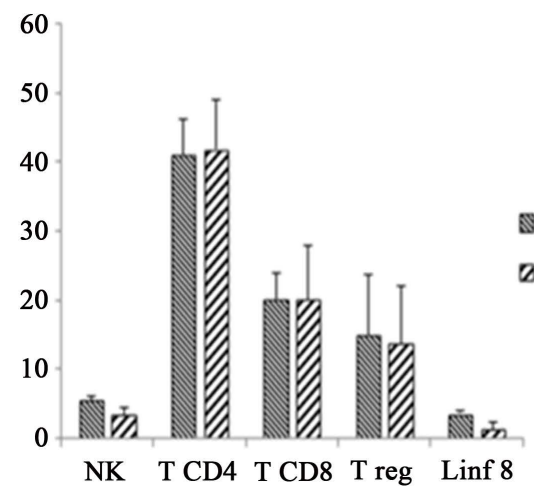

(c)

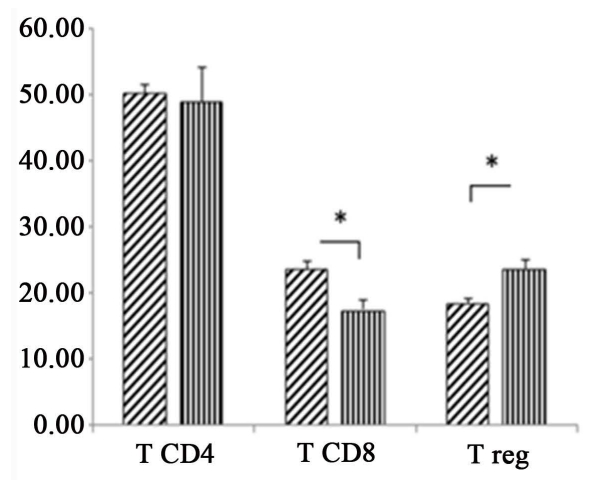

(e)

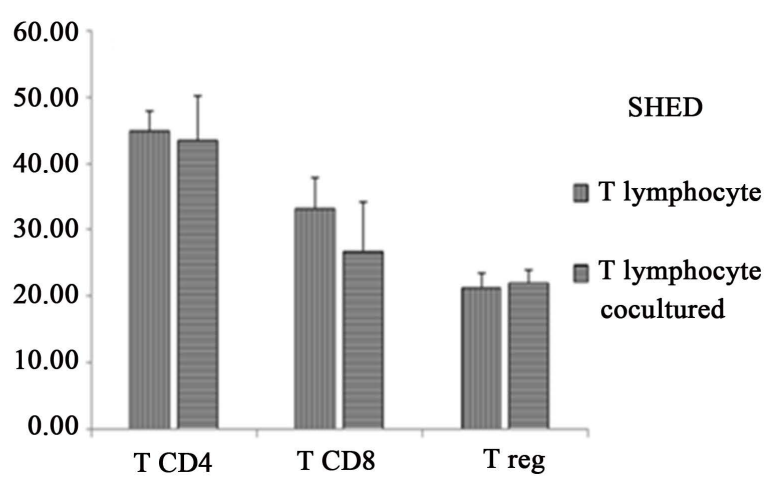

(b)

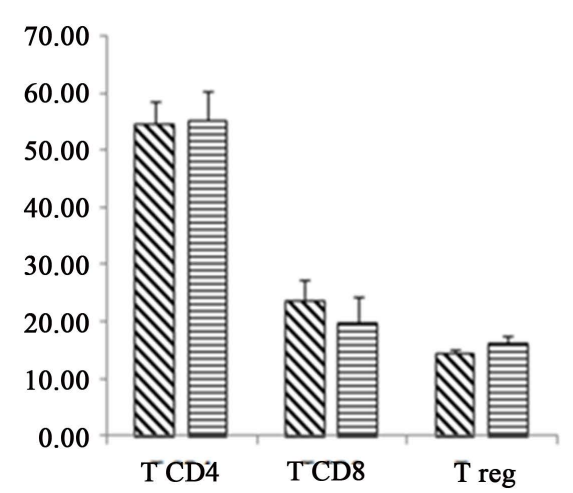

(d)

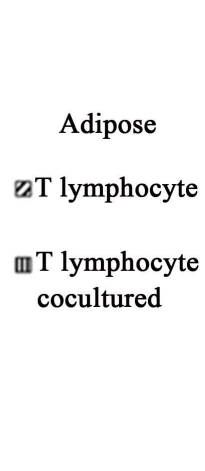

Bone Marrow

\$T lymphocyte

$\boxminus$ T lymphocyte cocultured
Adipose

2 $\mathrm{PBMC}$

$\square$ PBMC cocultured

Figure 4. Effect of adipocyte derived MSC (AD-MSC), Human Exfoliated Deciduous Teeth derived MSC (SHED-MSC) and bone marrow derived MSC (BM-MSC). (a) SHED-MSC co-cultured with PBMC compared to control, statistically decreased Treg $(\mathrm{p}=0.01)$ and $\mathrm{CD}^{+}(\mathrm{p}=0.02)$ lymphocyte; (b) SHED-MSC co-cultured with isolated T cells compared to control did not have a significant influence on T cell subsets; (c) BM-MSC co-cultured with PBMC compared to control did not significantly influence T lymphocytes subsets neither from PBMC nor isolated T cells; (d) BM-MSC co-cultured with isolated $\mathrm{T}$ cells compared to control also did not have influence in T lymphocytes subsets; (e) AD-MSC co-cultured with PBMC compared to control, statistically decreased B lymphocyte $(\mathrm{p}=0.04)$; (f) AD-MSC co-cultured with isolated T cells compared to control, statistically decreased $\mathrm{CD}^{+}(\mathrm{p}=0.008)$ and increased Treg $(\mathrm{p}=0.01)$ lymphocytes.

\subsection{LP Has Different Lymphocyte Subset Stimulation}

To address if LP can increase any type of lymphocyte subset, we compared PBMC and T cells proliferation and immune phenotype cultured with SBF or LP. Either from PBMC or isolated T cells, PL alone significantly ( $\mathrm{p}=$ 0.01 and $\mathrm{p}=0.02$, respectively) increased Treg expression. Furthermore, differently from MSC, LP does not change proliferation prolife among the groups (Figure 5). 


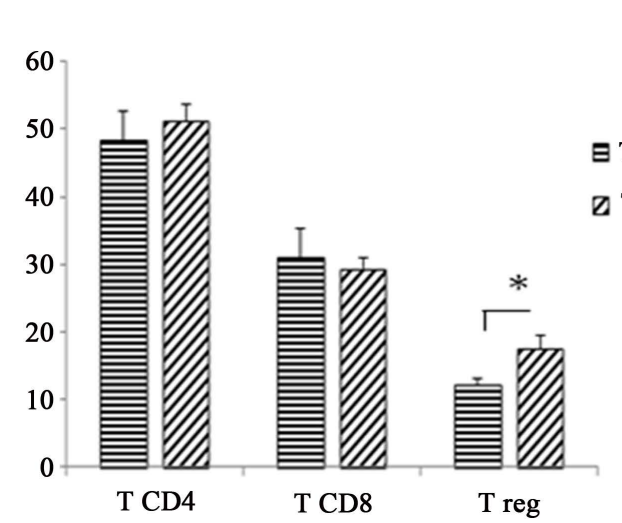

(a)

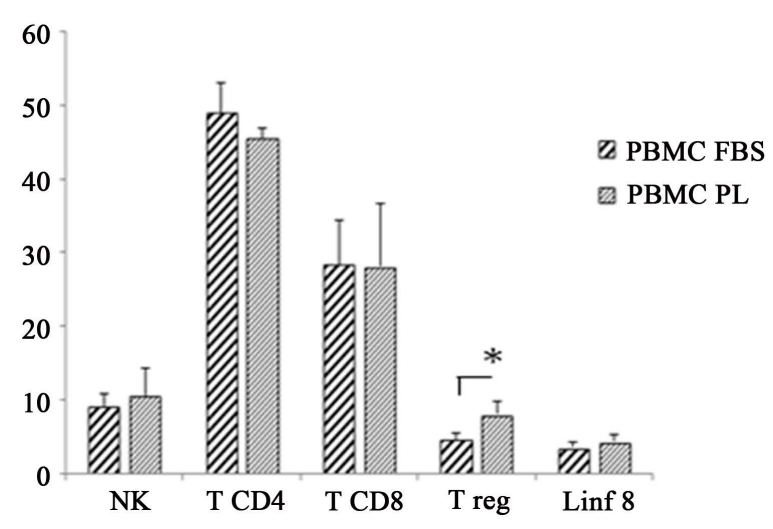

(b)

Serum $\times$ PL

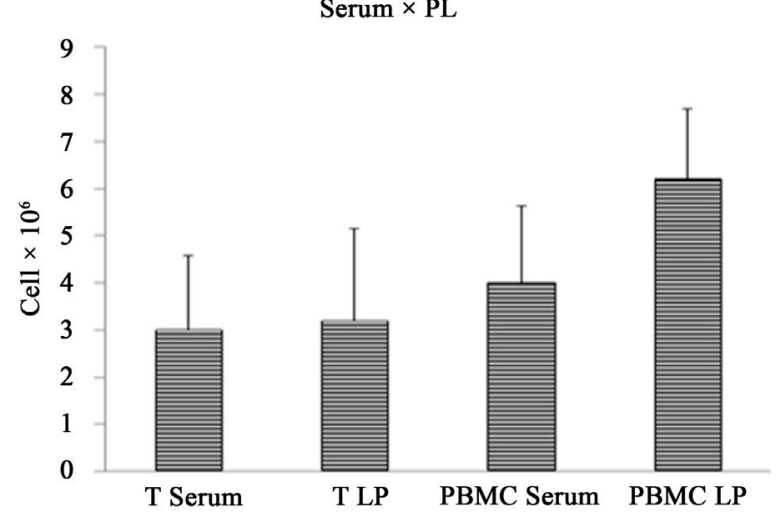

(c)

Figure 5. Comparison of platelet lysate (LP) and fetal bovine serum (FBS) effect on proliferation and lymphocytes subsets. (a) isolated T cells cultured with LP and FBS, LP significantly $(\mathrm{p}=0.02)$ induce T reg phenotype; (b) PBMC cultured with LP and FBS, LP significantly ( $p=0.01$ ) induce T reg phenotype; (c) proliferative potential of PBMC or isolated T cells with PL or FCS did not differ when cultured with PL or FCS.

\section{Discussion}

Mesenchymal stromal cells are been tested in clinical trials for the treatment of several immune related diseases [17], as well as, in regenerative medicine [18]. MSC, along with other mesodermal derived cells, are present in several organs and tissues stroma and its regenerative and imunomodulation potential might variate with the different millieu it is obtained of. Here we show the results of co-culturing MSC from three different sources: adipocyte, bone marrow and SHED with unsepareted PBMC and CD3 ${ }^{+}$isolated T cells. Additionally, different human derived supplements for cell cultures are been tested in order to avoid unwanted xenoreactions already described when fetal calf serum is utilized as supplement [19].

As showed by others [20], in our hands, AD-MSC exhibited a significant superior proliferative (Figure 2) and immunomodulation effect (Figure 3). BM and SHED derived MSC tent to decrease T cells subsets (CD4, CD8, Treg, NK lymphocytes) either from unsepareted PBMC or isolated T cells. SHED-MSCs, however, were able to significantly decrease $\mathrm{CD} 4^{+}$and Tregs $\left(\mathrm{p}=0.02\right.$ and $\mathrm{p}=0.01$, respectively), the $\mathrm{CD} 4^{+}$decrease subset could, however, be secondary to the decrease observed in Tregs, since both belong to the CD4 subset.

AD-MSCs not only exhibited a higher proliferative capacity but also were able to significantly $(p=0.04)$ decrease B cells from PBMC.. When co-cultured with purify T cells AD-MSC significantly decrease $\mathrm{CD}^{+}(\mathrm{p}=$ $0.008)$ cells and increase Tregs $(p=0.01)$. Additionaly, to test a possible influence of the type of supplement utilized in MSC cultures, we showed that platelet lisate also have an independent immunomodulation effect: it significantly increases Tregs when utilized as a supplement for PBMC or T lymphocytes $\mathrm{p}=0.01$ and $\mathrm{p}=0.02$, respectively (Figure 5). However, the observed increase in Tregs in co-cultures with T lymphocytes cannot be attributed to the use of PL alone, since all cultures, from all sources were tested in the presence of PL and only 
the AD-MSC/Tcell co-culture effectivelly increased Tregs.

$\mathrm{T}$ regulatory cells are known to modulate graft versus host disease (GVHD) [21] and autoimmunity [22]. AD-MSC might turn out to be the ideal type of MSC to be tested in cellular therapy trials for theses diseases. In this study, co culture of AD-MSC and magneticaly purified $\mathrm{T}$ cells, significantly increased Treg cells. In accordance with literature [10] this effects could be a mechanism for immunesuppresion.

As stated above, SHED when cultured with PBMC were significantly effective in decresing T CD $4^{+}$cells and Tregs, an effect that could be attributed to the fact that in cases of agression and lymphocyte infiltration, pulp MSC allows T CD8 $8^{+}$infiltration and expansion in a dose dependent manner in the presence of bacterial or fungal infections, decreasing $\mathrm{CD}^{+}$numbers [23] [24]. SHED-MSC could be utilized in such clinical settings.

In accordance with Lee et al. [25], we demosntrated that LP alone can increase Treg phenothype. A study on the effects of MSC of different sources cultured either with FCS or PL is underway to see if the observed PL related Tregs increase can affect MSC from different tissues. Finally, TGF- $\beta$ known to be present in PL can strongly induce Treg phenotype and MSC homing in GVHD [26] [27]. PL effect on Tregs might be attributed to this growth factor [28] [29].

\section{Conclusion}

Adipocyte derived MSC, among other tissue derived MSC, can proliferate better and among other MSC sources is more efficient in inducing immunoregulatory cells. BM derived MSC is an approved cellular therapy for steroid resistant GVHD, and is being tested for a variaty of inflamatory diseases. BM derived cells are suited for cellular therapy because they are obtained from a healthy hematopoietic stem cell transplant donor tested for all known microbial infections. Lipoaspirate, on the other hand, is usually obtained from plastic surgery, where possible infective pathogens are not taken into consideration. Autologous lipoaspirate in the setting of an inflamatory disease is a rather invasive procedure. In spite of that, adipocyte derived MSC cultured with PL, might be the best type of MSC for the treatment of inflamatory or autoimmune disease.

\section{Acknowledgements}

The study received financial support from Hopital de Clinicas de Porto Alegre investment Research fund (FIPE-HCPA) and Conselho Nacional de Pesquisa-CNPq.

\section{Conflict of Interrest}

The authors declare no conflict of interests.

\section{References}

[1] Friedenstein, A.J., Chailakhyan, R.K. and Gerasimov, U.V. (1987) Bone Marrow Osteogenic Stem Cells: In Vitro Cultivation and Transplantation in Diffusion Chambers. Cell and Tissue Kinetics, 20, 263-272. http://dx.doi.org/10.1111/j.1365-2184.1987.tb01309.x

[2] Friedenstein, A.J., Gorskaja, J.F. and Kulagina, N.N. (1976) Fibroblast Precursors in Normal and Irradiated Mouse Hematopoietic Organs. Experimental Hematology, 4, 267-274.

[3] Wang, Y., Chen, X., Cao, W. and Shi, Y. (2014) Plasticity of Mesenchymal Stem Cells in Immunomodulation: Pathological and Therapeutic Implications. Nature Immunology, 15, 1009-1016. http://dx.doi.org/10.1038/ni.3002

[4] Laranjeira, P., Pedrosa, M., Pedreiro, S., Gomes, J., Martinho, A., Antunes, B., Ribeiro, T., Santos, F., Trindade, H. and Paiva, A. (2015) Effect of Human Bone Marrow Mesenchymal Stromal Cells on Cytokine Production by Peripheral Blood Naïve. Memory and Effector T Cells, 6, 1-14.

[5] Yu, B., Zhang, X. and Li, X. (2014) Exosomes Derived from Mesenchymal Stem Cells. International Journal of Molecular Sciences, 15, 4142-4157. http://dx.doi.org/10.3390/ijms15034142

[6] Via, A.G., Frizziero, A. and Oliva, F. (2012) Biological Properties of Mesenchymal Stem Cells from Different Sources. Muscle, Ligaments and Tendons Journal, 2, 154-162.

[7] Sousa, B.R., Parreira, R.C., Fonseca, E.A., Amaya, M.J., Tonelli, F.M.P., Lacerda, S.M.S.N., Lalwani, P., Santos, A.K., Gomes, K.N., Ulrich, H., Kihara, A.H. and Resende, R.R. (2014) Human Adult Stem Cells from Diverse Origins: An Overview from Multiparametric Immunophenotyping to Clinical Applications. Cytometry Part A, 85, 43-77. http://dx.doi.org/10.1002/cyto.a.22402 
[8] Jin, H., Bae, Y., Kim, M., Kwon, S.-J., Jeon, H., Choi, S., Kim, S., Yang, Y., Oh, W. and Chang, J. (2013) Comparative Analysis of Human Mesenchymal Stem Cells from Bone Marrow, Adipose Tissue, and Umbilical Cord Blood as Sources of Cell Therapy. International Journal of Molecular Sciences, 14, 17986-18001. http://dx.doi.org/10.3390/ijms140917986

[9] Silla, L., Valim, V., Amorin, B., Alegretti, A.P., Dos Santos de Oliveira, F., Lima da Silva, M.A., Dahmer, A., Emerim Lemos, N., Mentz Albrecht, M.A., Macedo Laureano, Á., Bonfim, C., Moraes Júnior, L., Pezzi, A., Baggio, L., Albrecht, C.A.M., Capra, M., Fogliatto, L., Della Costa Rigoni, L., Fischer, G., Paz, A. and Esteves Daudt, L. (2014) A Safety and Feasibility Study with Platelet Lysate Expanded Bone Marrow Mesenchymal Stromal Cells for the Treatment of Acute Graft-versus-Host Disease in Brazil. Leukemia \& Lymphoma, 55, 1203-1205. http://dx.doi.org/10.3109/10428194.2013.823495

[10] Iudicone, P., Fioravanti, D., Bonanno, G., Miceli, M., Lavorino, C., Totta, P., Frati, L., Nuti, M. and Pierelli, L. (2014) Pathogen-Free, Plasma-Poor Platelet Lysate and Expansion of Human Mesenchymal Stem Cells. Journal of Translational Medicine, 12, 28. http://dx.doi.org/10.1186/1479-5876-12-28

[11] Horwitz, E.M., Le Blanc, K., Dominici, M., Mueller, I., Slaper-Cortenbach, I., Marini, F.C., Deans, R.J., Krause, D.S. and Keating, A. (2005) Clarification of the Nomenclature for MSC: The International Society for Cellular Therapy Position Statement. Cytotherapy, 7, 393-395. http://dx.doi.org/10.1080/14653240500319234

[12] Haddad, R. and Saldanha-Araujo, F. (2014) Mechanisms of T-Cell Immunosuppression by Mesenchymal Stromal Cells: What Do We Know so Far? BioMed Research International, 2014, 1-14. http://dx.doi.org/10.1155/2014/216806

[13] Zuk, P.A., Zhu, M., Mizuno, H., Huang, J., Futrell, J.W., Katz, A.J., Benhaim, P., Lorenz, H.P. and Hedrick, M.H. Multilineage Cells from Human Adipose Tissue: Implications for Cell-Based Therapies. Tissue Engineering, 7, 211228. http://dx.doi.org/10.1089/107632701300062859

[14] Capelli, C., Domenghini, M., Borleri, G., Bellavita, P., Poma, R., Carobbio, A., Micò, C., Rambaldi, A., Golay, J. and Introna, M. (2007) Human Platelet Lysate Allows Expansion and Clinical Grade Production of Mesenchymal Stromal Cells from Small Samples of Bone Marrow Aspirates or Marrow Filter Washouts. Bone Marrow Transplant, 40, 785791. http://dx.doi.org/10.1038/sj.bmt.1705798

[15] Gronthos, S., Mankani, M., Brahim, J., Robey, P.G. and Shi, S. (2000) Postnatal Human Dental Pulp Stem Cells (DPSCs) in Vitro and in Vivo. Proceedings of the National Academy of Sciences of the United States of America, 97, 13625-13630. http://dx.doi.org/10.1073/pnas.240309797.

[16] Rasmusson, I., Ringdén, O., Sundberg, B. and Le Blanc, K. (2005) Mesenchymal Stem Cells Inhibit Lymphocyte Proliferation by Mitogens and Alloantigens by Different Mechanisms. Experimental Cell Research, 305, 33-41. http://dx.doi.org/10.1016/j.yexcr.2004.12.013

[17] Le Blanc, K., Rasmusson, I., Sundberg, B., Götherström, C., Hassan, M., Uzunel, M. and Ringdén, O. (2004) Treatment of Severe Acute Graft-versus-Host Disease with Third Party Haploidentical Mesenchymal Stem Cells. The Lancet, 363, 1439-1441. http://dx.doi.org/10.1016/S0140-6736(04)16104-7

[18] Caplan, A.I. and Correa, D. (2011) The MSC: An Injury Drugstore. Cell Stem Cell, 9, 11-15. http://dx.doi.org/10.1016/j.stem.2011.06.008

[19] Hemeda, H., Giebel, B. and Wagner, W. (2014) Evaluation of Human Platelet Lysate versus Fetal Bovine Serum for Culture of Mesenchymal Stromal Cells. Cytotherapy, 16, 170-180. http://dx.doi.org/10.1016/j.jcyt.2013.11.004

[20] Mohammadzadeh, A., Pourfathollah, A.A., Shahrokhi, S., Hashemi, S.M., Moradi, S.L.A. and Soleimani, M. (2014) Immunomodulatory Effects of Adipose-Derived Mesenchymal Stem Cells on the Gene Expression of Major Transcription Factors of T Cell Subsets. International Immunopharmacology, 20, 316-321. http://dx.doi.org/10.1016/j.intimp.2014.03.003

[21] Socié, G. and Blazar, B.R. (2009) Acute Graft-versus-Host Disease: From the Bench to the Bedside. Blood, 114, 43274736. http://dx.doi.org/10.1182/blood-2009-06-204669

[22] Wing, K. and Sakaguchi, S. (2010) Regulatory T Cells Exert Checks and Balances on Self Tolerance and Autoimmunity. Nature Immunology, 11, 7-13. http://dx.doi.org/10.1038/ni.1818

[23] Durutürk, L., Sarı, S. and Sengül, A. (2013) Immunocompetent Cell Level as a Diagnostic Reference for Pulpal Pathosis of Primary Teeth. Archives of Oral Biology, 58, 1517-1522. http://dx.doi.org/10.1016/j.archoralbio.2013.04.010

[24] Hahn, C.L., Best, A.M. and Tew, J.G. (2000) Cytokine Induction by Streptococcus mutans and Pulpal Pathogenesis. Infection and Immunity, 68, 6785-6789. http://dx.doi.org/10.1128/IAI.68.12.6785-6789.2000

[25] Lee, Y.-L., Lee, L.-W., Su, C.-Y., Hsiao, G., Yang, Y.-Y., Leu, S.-J., Shieh, Y.-H. and Burnouf, T. (2013) Virally Inactivated Human Platelet Concentrate Lysate Induces Regulatory T Cells and Immunosuppressive Effect in a Murine Asthma Model. Transfusion, 53, 1918-1928. http://dx.doi.org/10.1111/trf.12068 
[26] Paczesny, S., Raiker, N., Brooks, S. and Mumaw, C. (2013) Graft-versus-Host Disease Biomarkers: Omics and Personalized Medicine. International Journal of Hematology, 98, 275-292. http://dx.doi.org/10.1007/s12185-013-1406-9

[27] Visentainer, J.E.L., Lieber, S.R., Persoli, L.B.L., Vigorito, A.C., Aranha, F.J.P., de Brito Eid, K.A., Oliveira, G.B., Miranda, E.C.M. and de Souza, C.A. (2003) Serum Cytokine Levels and Acute Graft-versus-Host Disease after HLA-Identical Hematopoietic Stem Cell Transplantation. Experimental Hematology, 31, 1044-1050. http://dx.doi.org/10.1016/S0301-472X(03)00264-9

[28] Fekete, N., Gadelorge, M., Fürst, D., Maurer, C., Dausend, J., Fleury-Cappellesso, S., Mailänder, V., Lotfi, R., Ignatius, A., Sensebé, L., Bourin, P., Schrezenmeier, H. and Rojewski, M.T. (2012) Platelet Lysate from Whole Blood-Derived Pooled Platelet Concentrates and Apheresis-Derived Platelet Concentrates for the Isolation and Expansion of Human Bone Marrow Mesenchymal Stromal Cells: Production Process, Content and Identification of Active Comp. Cytotherapy, 14, 540-554. http://dx.doi.org/10.3109/14653249.2012.655420

[29] Horwitz, D.A., Zheng, S.G., Wang, J. and Gray, J.D. (2008) Critical Role of IL-2 and TGF-Beta in Generation, Function and Stabilization of Foxp3+CD4+ Treg. European Journal of Immunology, 38, 912-915.

http://dx.doi.org/10.1002/eji.200738109 